\title{
Sparse-Spike Deconvolution Promoting Frequency Dependent Seismic Stratigraphic Analysis and an Application
}

\author{
LIU Chang ${ }^{1,2}$ \\ 1. China United Coalbed Methane Corporation Ltd., Beijing 100016, China \\ 2. Unconventional Oil \& Gas Branch, CNOOC Ltd., Beijing 100016, China
}

\begin{abstract}
Low-frequency components of seismic data tend to characterize thicker litho-stratigraphic units, while high-frequency components tend to characterize thinner isochronous-stratigraphic units. Thus, frequency dependent interpretation can help to achieve fine sedimentary sequence analysis. However, in current seismic sedimentology method, a certain frequency profile generated by frequency filtering, loses some stratum reflection information, which is out of the limited frequency band. To achieve real frequency dependent stratum reflection profiles with whole stratum information, a time-varying sparse-spiking deconvolution based method is proposed in this paper. A synthetic example and a real delta progradation example show the accuracy and effectiveness of proposed method.
\end{abstract}

Key words: Sparse-spike deconvolution, frequency dependent interpretation, seismic stratigraphic analysis, seismic sedimentology.

\section{Introduction}

The frequency dependent seismic sequence analysis is an important explanation technique of seismic sedimentology [1, 4]. The term "Seismic Sedimentology" is first put forward by Zeng in the article of making stratigraphic section by using seismic data $[5,6]$. It is a subject which applies advanced geophysical processing and interpretation techniques to study sedimentary rocks and their forming processes. Afterwards, a group of scholars at homeland and abroad have done a lot of researches in the theory and application of seismic sedimentology [7-9]. $90^{\circ}$ phase transformation [10, 11], strata slice [12] and frequency dependent seismic sequence analysis [13, 14], as the three key technologies in seismic sedimentology, have been the valid tools for the study of high frequency sequence and sedimentary system, also functioning well in the application of thin sand body exploration

Corresponding author: Liu Chang, Master, Engineer, research fields: sedimentology and reservoir geology. and development $[15,16]$.

The low frequency components of seismic data tend to characterize thicker litho-stratigraphic units, while high frequency components tend to characterize thinner isochronous-stratigraphic units. Therefore, frequency dependent interpretation, as one of the key techniques in seismic sedimentology, can help to achieve fine sedimentary sequence analysis. However, the dominant frequency of seismic event varies with stratum, a certain frequency profile generated by frequency filtering [13], loses some stratum reflection information which is out of the limited frequency band in current seismic sedimentology method, thus affecting sequence analysis. Although the time-frequency decomposition method [17] is better than the frequency filtering method in time-frequency resolution and reservoir identification [18-20], it has the same problem as the frequency filtering method in the application of frequency-division sequence analysis [21, 22], which can not get the true frequency-division reflection profile of the whole 
formation information.

To achieve real frequency dependent stratum reflection profiles with whole stratum information, a time-varying sparse-spiking deconvolution based method is proposed in this paper [23, 24]. This method is about seeking stratum reflection coefficient with sparse-spiking deconvolution in the given estimation seismic wavelet and sparse constraint conditions. The expected frequency dependent profile with whole strata information is obtained by the convolution of acquired stratum reflection coefficient and expected frequency wavelet. Therefore, we can acquire thin sequence clearly for fine sequence analysis which cannot be seen in original seismic profile. A synthetic example and a real delta progradation example show the accuracy and effectiveness of proposed method.

\section{Method and Theory}

Seismic record can be obtained by the convolution of seismic wavelet and stratum reflection coefficient.

$$
s(t)=w(t) * r(t)
$$

where $s(t)$ is seismic record, $w(t)$ is seismic wavelet, $r(t)$ is stratum reflection coefficient, * is convolution operation.

By means of Fourier transform, Eq. (1) can be expressed as Eq. (2) in the frequency domain.

$$
S(\omega)=W(\omega) \times R(\omega)
$$

where $\omega=2 \pi f, f$ is frequency (Hz), $S(\omega)$ is seismic record frequency spectrum, $W(\omega)$ is seismic wavelet spectrum, $R(t)$ is stratum reflection coefficient spectrum.

From Eq. (2), it can be seen that only the stratum reflection coefficient spectrum and wavelet spectrum are both strong enough, frequency components tend to be strengthened. Stratum reflection coefficient frequency spectrum is constant, therefore, changing the input seismic wavelet frequency components will make the seismic profiles of geological strata information have different response. By means of inputting different seismic wavelet frequency components, we can obtain a variety of different interpretations and dig up more comprehensive stratigraphic sequence information, which is the basic principle of separate frequency interpretation.

Because the true frequency dependent seismic reflection profiles are hard to get, in order to replace the profiles approximately, in current seismic sedimentology method, a certain frequency profile is generated by frequency filtering which loses some stratum reflection information. A time-varying sparse-spiking deconvolution based method is proposed in this paper. This method is about seeking stratum reflection coefficient with sparse-spiking deconvolution in the given estimation seismic wavelet and sparse constraint conditions. The expected frequency dependent profile with whole strata information is obtained by the convolution of acquired stratum reflection coefficient and expected frequency wavelet. Consequently, all the formation interfaces will be considered in the each frequency dependent reflection profile.

Since the frequency of lineups in seismic profile is time-varying, therefore, Eq. (1) is changed into the convolution model which is closer to the real situation.

$$
s(t)=\sum_{k=1}^{K}\left[w_{k}(t) * r_{k}(t)\right]
$$

where $w_{k}$ is the wavelet with frequency $k, r_{k}$ is the corresponding reflection coefficient, $K$ is the total number of the frequency components in the seismic record.

Eq. (3) can be rewritten into the linear form [25].

$$
\boldsymbol{s}=\sum_{k=1}^{K}\left[\boldsymbol{W}_{k} \boldsymbol{r}_{k}\right]=\mathbf{C m}
$$

where $W_{k}$ is the convolution matrix of wavelet $w_{k}$, $\boldsymbol{C}=\left(\boldsymbol{W}_{1} \boldsymbol{W}_{2} \mathrm{~L} \boldsymbol{W}_{k}\right)$ is the convolution matrix library, $\boldsymbol{m}=\left(\begin{array}{lll}\boldsymbol{r}_{1} & \boldsymbol{r}_{2} \mathrm{~L} & \boldsymbol{r}_{k}\end{array}\right)^{\mathrm{T}}$ is the frequency dependent reflection coefficient.

Stratum reflection coefficient is the summation of the reflection coefficients with frequency $k$.

$$
r(t)=\sum_{k=1}^{K} r_{k}(t)
$$


To solve Eq. (4) through the advanced sparse-spiking deconvolution based method [25], we can get the final stratum reflection coefficient. And then, frequency dependent profiles will be obtained by the convolution of reflection coefficients and wavelets which contain different frequency components.

$$
s_{k}(t)=w_{k}(t) * r(t)
$$

where $s_{k}(t)$ is the frequency dependent strata reflection profile with the dominant frequency $k$.

\section{Forward Modeling}

A forward model is designed to verify the accuracy and effectiveness of the proposed method in seismic sedimentology (Fig. 1). As is shown in Fig. 1, Fig. 1a is for the reflection coefficients model and Fig. $1 \mathrm{~b}$ is synthetic seismic data which ensure that the forward modeling seismic record contains multiple frequencies.

Fig. 2 shows the true frequency dependent seismic reflection profiles which are derived from the convolution between real reflection coefficients and specific frequency wavelet. Through the seismic reflection profiles, we can see that low frequency (15 $\mathrm{Hz}$ ) profile tends to characterize thicker litho-stratigraphic units and high frequency $(70 \mathrm{~Hz})$ profile tends to characterize thinner isochronous-stratigraphic units. While in the

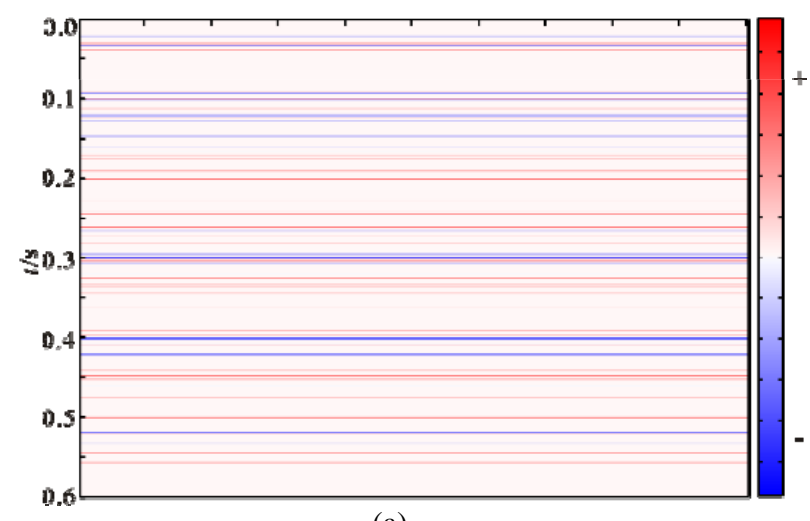

(a)

Fig. 1 Forward model. (a) Reflection coefficients model. 65 coefficients random spread over $0 \sim 0.6$ s, characterize thinner isochronous sediment interfaces. 5 bigger coefficients at $0.1 \mathrm{~s}, 0.2 \mathrm{~s}, 0.3 \mathrm{~s}, 0.4 \mathrm{~s}$ and $0.5 \mathrm{~s}$ characterize thicker lithology change interfaces. (b) Synthetic seismic data. The dominant frequency of each wavelet at corresponding reflective interface is chosen in between $15 \mathrm{~Hz}$ and $65 \mathrm{~Hz}$ randomly. intermediate frequency (35 Hz) profile, the thicker litho-stratigraphic units and the thinner isochronous-stratigraphic units are shown together.

Two frequency dependent reflection profiles are shown in Figs. 3 and 4 respectively, which are derived from the seismic records (Fig. 1b). One is for frequency filtering method which is commonly used in the frequency dependent interpretation of seismic sedimentology (Fig. 3). The other is for sparse-spike deconvolution method which is proposed in this paper (Fig. 4).

Frequency dependentreflection profiles are obtained through the frequency filtering method which uses the gradient analysisin the frequency domain (Fig. 3). Compared these three profiles with the seismic reflection profiles in figure 2 respectively, there have large differences between the true frequency dependent seismic reflection profiles and the narrowband profiles which are obtained through the frequency filtering method. The main reason is that the dominant frequency of lineups in seismic records is different on the one hand, so that lose some stratum reflection information which is out of the limited frequency band. On the other hand, due to the weak information of effective wave, the low frequency components and high frequency components of seismic data are influenced by the truncation and noise seriously.

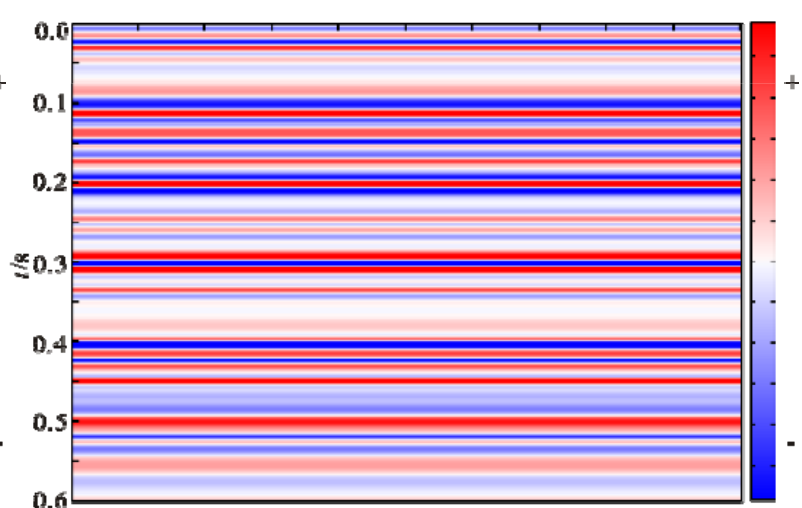

(b) 


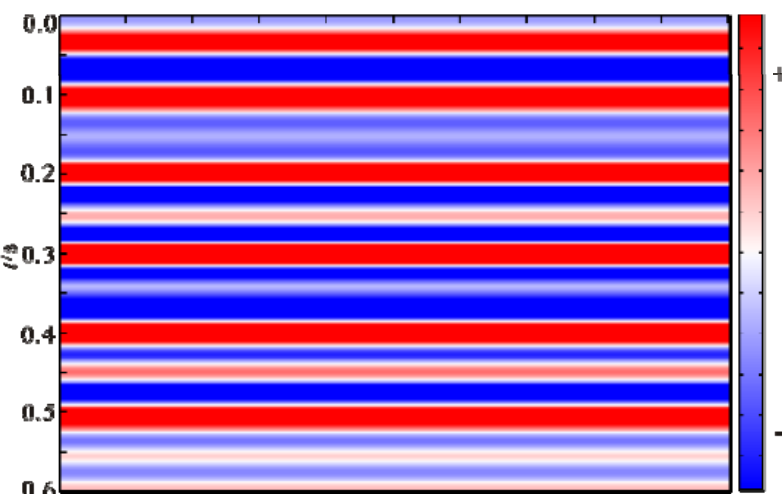

(a)

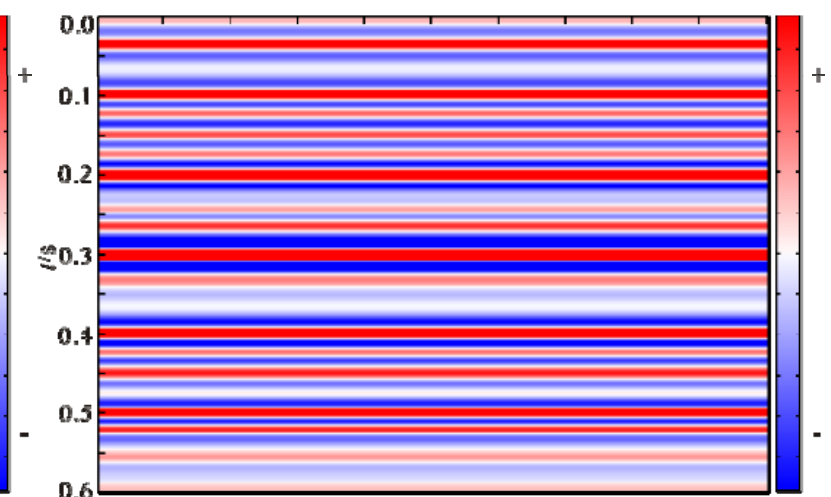

(b)

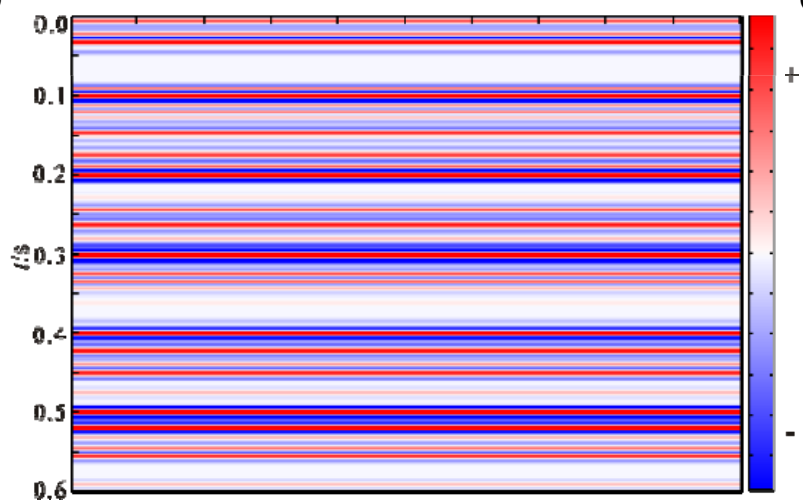

(c)

Fig. 2 True frequency dependent seismic reflection profiles. (a) $15 \mathrm{~Hz}$ dominant frequency profile; (b) $30 \mathrm{~Hz}$ dominant frequency profile; (c) $70 \mathrm{~Hz}$ dominant frequency profile.

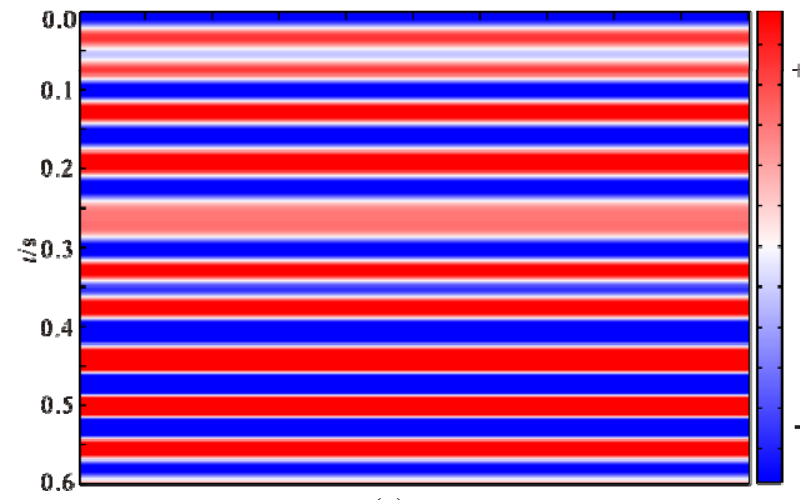

(a)

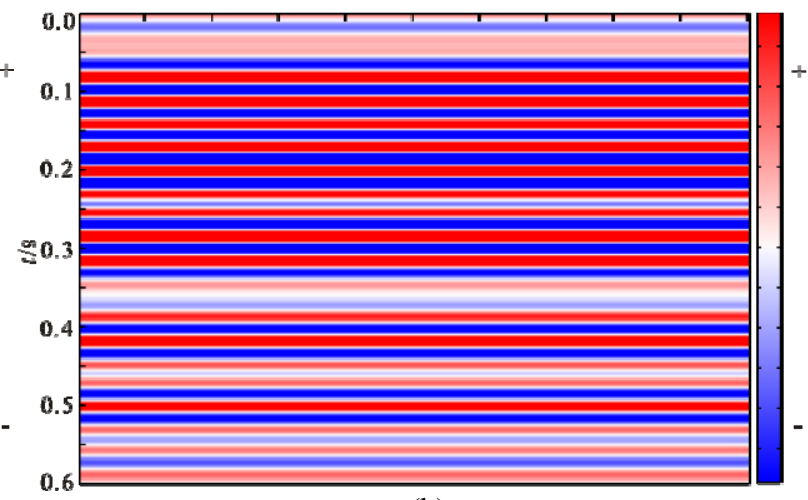

(b)

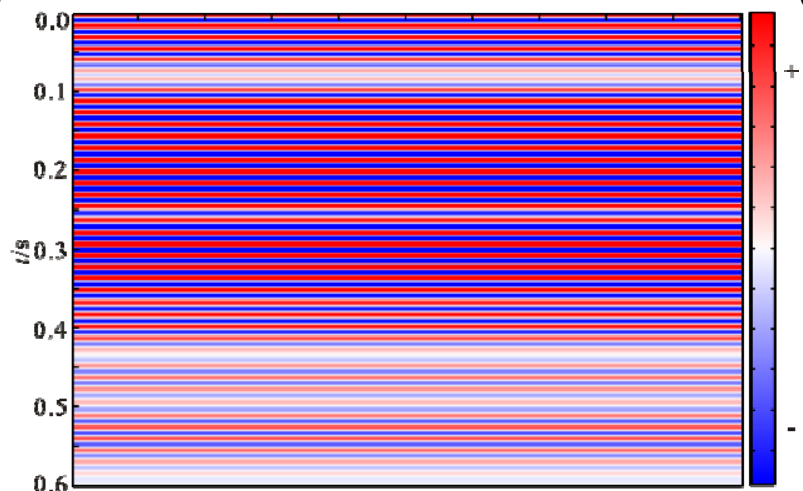

(c)

Fig. 3 Frequency dependent profiles by frequency filtering. (a) frequency range 5-10-20-25 Hz; (b) frequency range 20-25-35-40 Hz; (c) frequency range 60-65-75-80 Hz. 
Compared frequency dependent seismic reflection profiles (Fig. 4) with the seismic reflection profiles in Fig. 2 respectively, there are few differences between the true frequency dependent seismic reflection profiles and the frequency dependent seismic reflection profiles which are obtained through the proposed method so as to verify the accuracy and effectiveness of this method.

\section{Example}

A real delta progradation seismic sequence analysis example shows the accuracy and effectiveness of proposed method, which can better identify the typical progradation seismic reflection characteristics of delta front and provide the possibility to the division of fine sequence framework. Thus the results fit well with the actual work and make up for the deficiency of the previous work. Fig. 5 shows the deltaic progradation seismic profile, in the ellipse of figure is the key research part.

Through the conventional frequency filtering method, we get frequency dependent profiles which are shown in Fig. 6. Compared with the original seismic profile, we find the tendency that low frequency components of seismic data can reflect thicker litho-stratigraphic units and high frequency components of seismic data can reflect thinner isochronous-stratigraphic units by frequency filtering. However, two deficiencies exist in this method. On the one hand, in a certain frequency range, the frequency dependent profile loses some stratum reflection information which is out of the limited frequency band. On the other hand, especially in the high frequency profile, the seismic resolution is not high which is mainly affected by the truncation of the gradient analysis in the frequency domain (Figs. 6c and 6d).

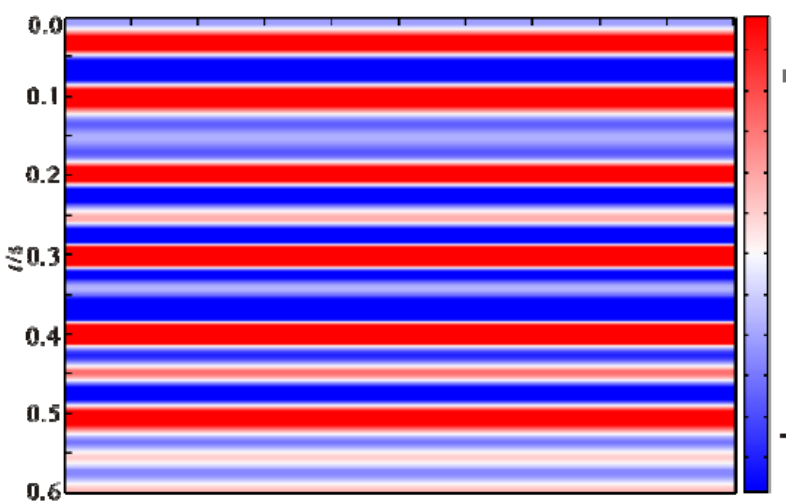

(a)

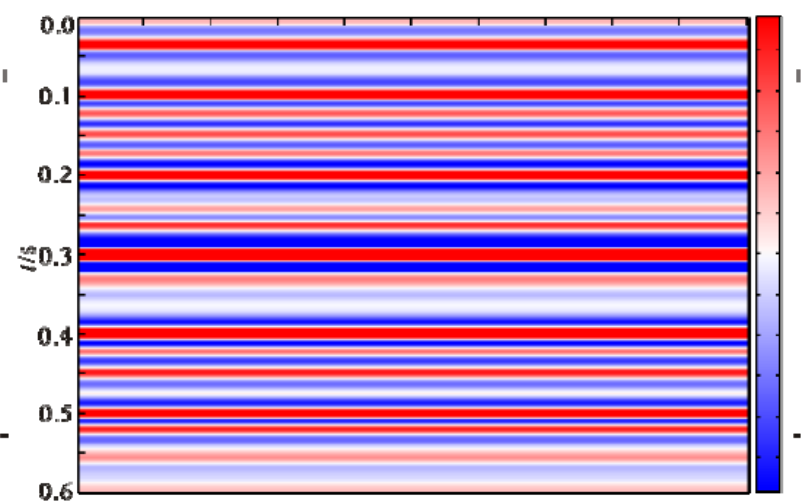

(b)

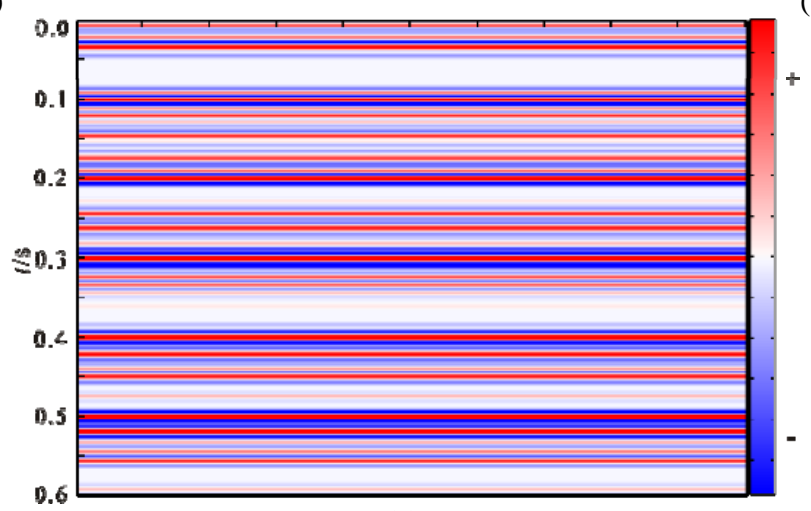

(c)

Fig. 4 Frequency dependent profiles by proposed method. (a) $15 \mathrm{~Hz}$ dominant frequency profile; (b) $30 \mathrm{~Hz}$ dominant frequency profile; (c) $70 \mathrm{~Hz}$ dominant frequency profile. 

Stratigraphic Analysis and an Application

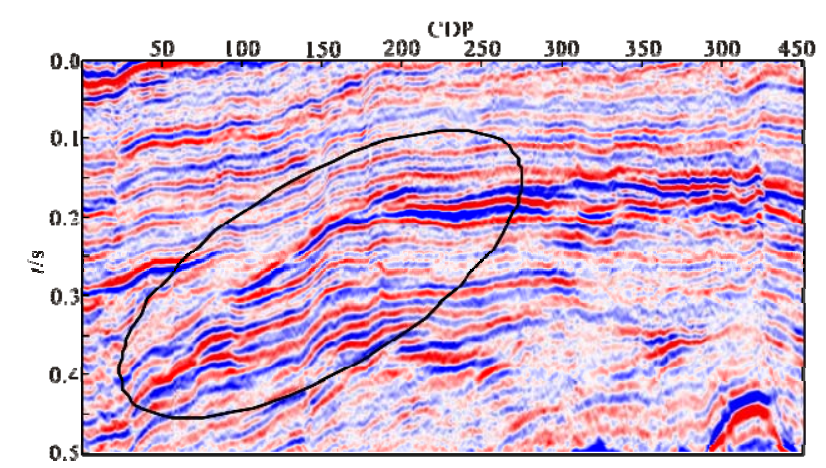

Fig. 5 Real seismic profile of deltaic progradation.

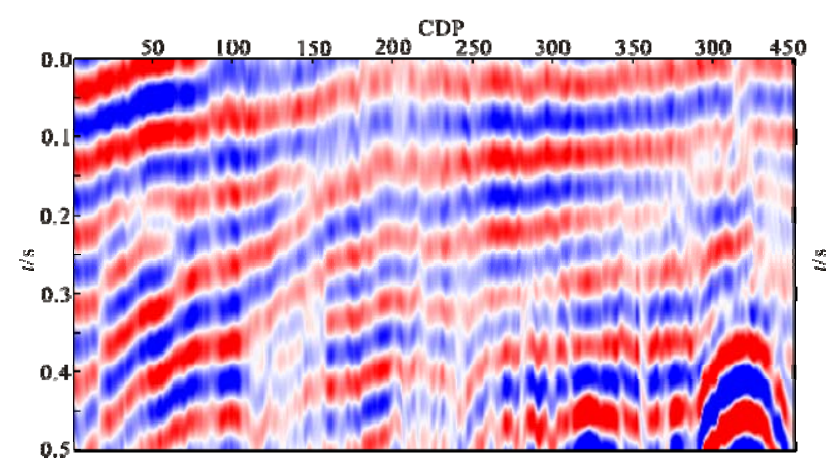

(a)

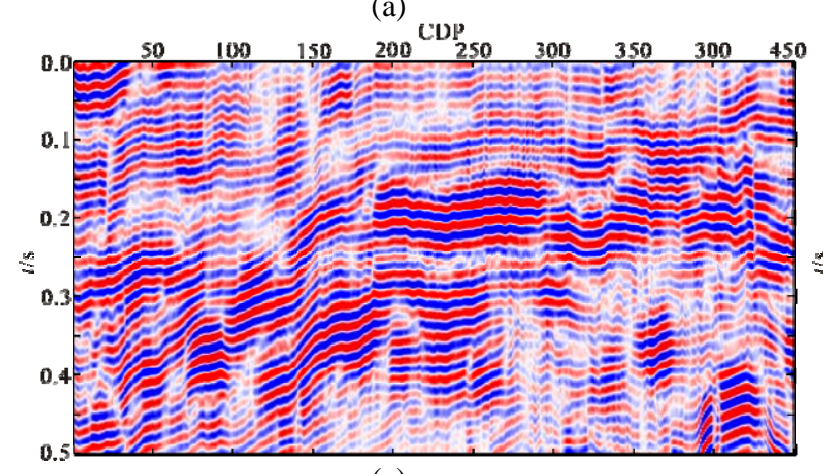

(c)

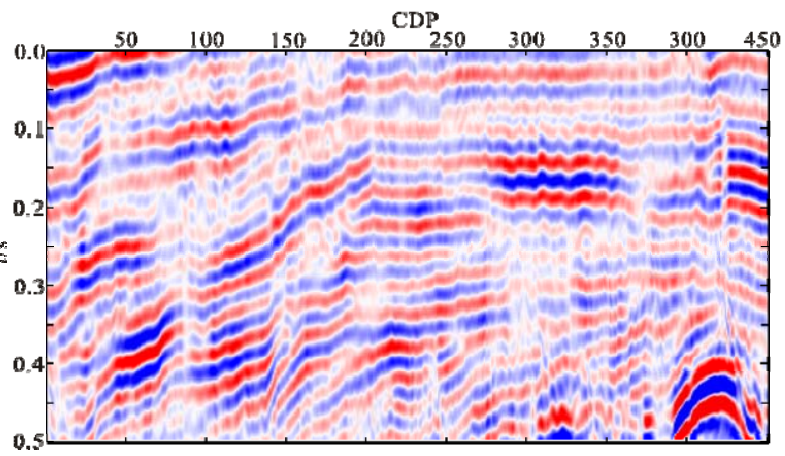

(b)

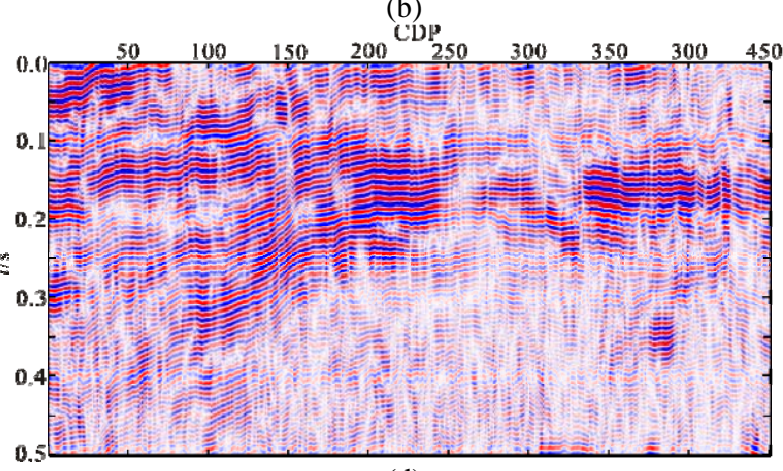

(d)

Fig. 6 Frequency dependent profiles by frequency filtering. (a) frequency range 5-8-12-15 Hz; (b) frequency range 10-15-25-30 Hz; (c) frequency range 30-35-45-50 Hz; (d) frequency range 70-75-85-90 Hz.

Through the proposed method in this paper, we get four frequency dependent profiles which are shown in Fig. 7. As is shown in the figure, two of the low frequency profiles tend to better characterize thicker litho-stratigraphic units, which can be used to divide the stratigraphic framework (Figs. 7a and 7b). The other two high frequency profiles tend to better characterize thinner isochronous-stratigraphic units which can be used in fine sequence analysis (Figs. 7c and 7d). Especially in the $80 \mathrm{~Hz}$ frequency profile, thin layers of sequence can be seen clearly which are not shown in the original seismic profile.
In order to show clearly, we compare the amplified black box part in Fig. 7 with the corresponding part of the original profile (Fig. 8). In the part of original seismic profile (Fig. 8a), thinner sedimentary sequence cannot be identified because of the resolution. While in the corresponding part of $80 \mathrm{~Hz}$ frequency profile by proposed method with high resolution, it can clearly show the thinner sequence.

In the actual work, we should make full use of the variety of materials and cooperate with each other, mainly using the low frequency to characterize the large-scale progradation, or reference to the original 


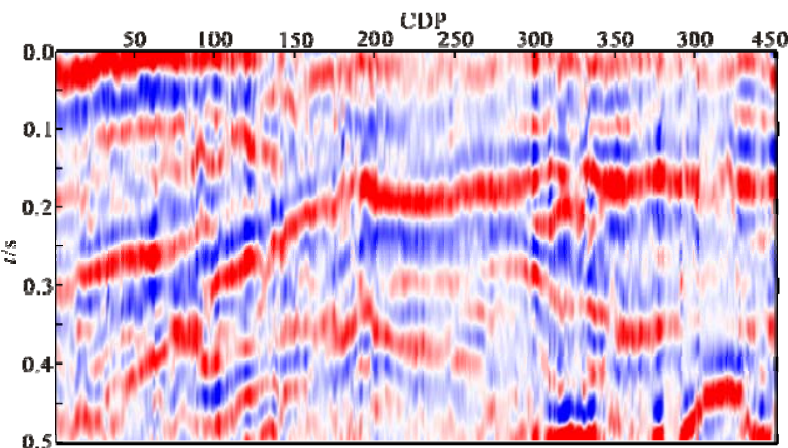

(a)
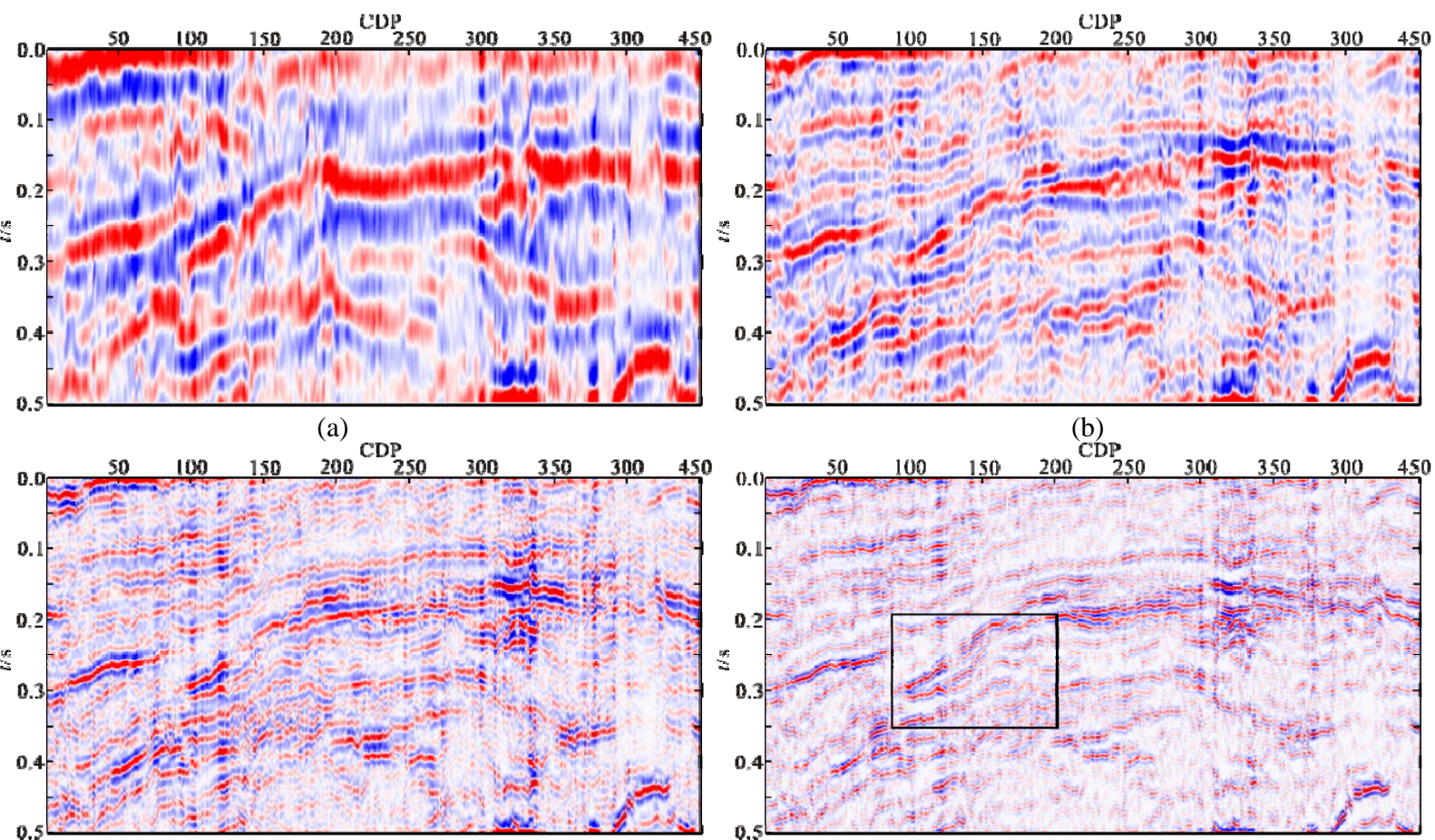

(c)

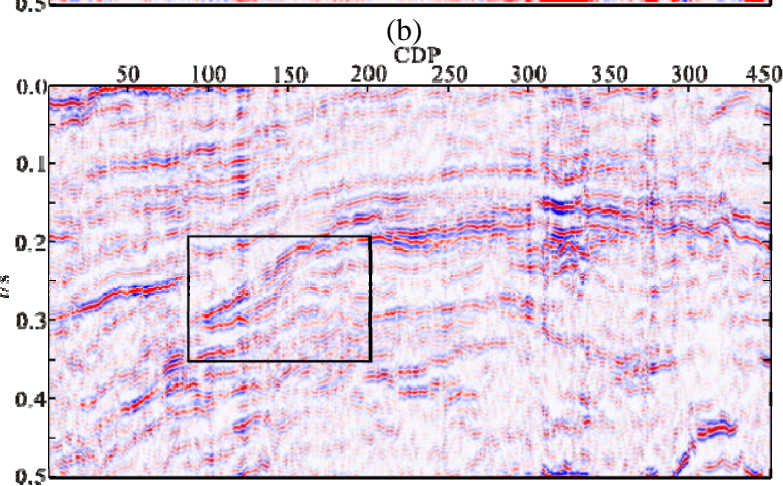

(d)

Fig. 7 Frequency dependent profiles by proposed method. (a) $10 \mathrm{~Hz}$ dominant frequency profile; (b) $20 \mathrm{~Hz}$ dominant frequency profile; (c) $40 \mathrm{~Hz}$ dominant frequency profile; (d) $80 \mathrm{~Hz}$ dominant frequency profile.

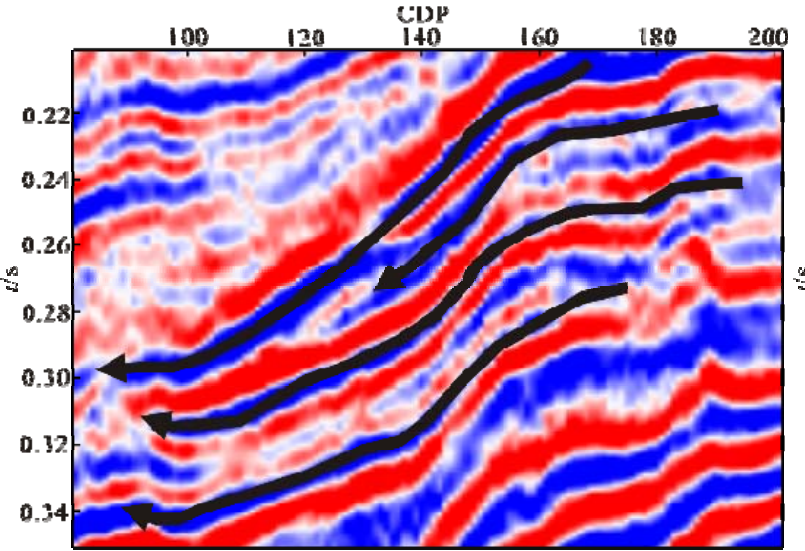

(a)

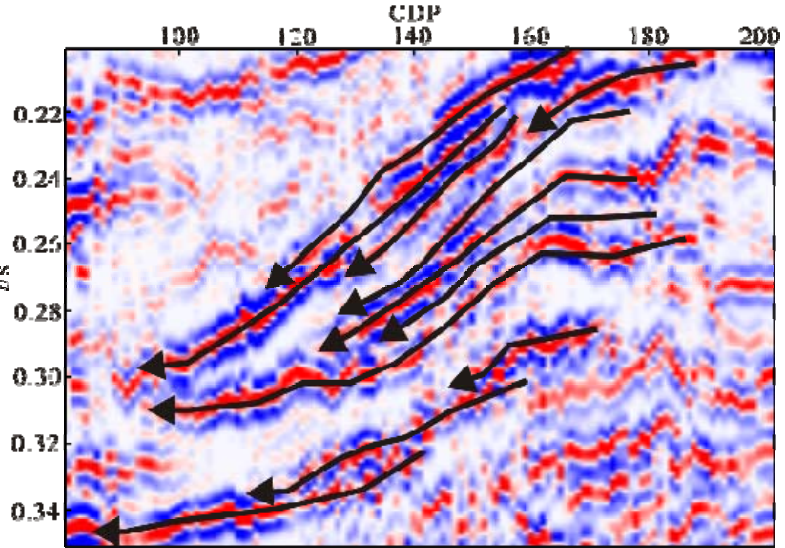

(b)

Fig. 8 Partial comparison of original profile and $80 \mathrm{~Hz}$ profile by proposed method. (a) Part of original seismic profile; (b) corresponding part of $80 \mathrm{~Hz}$ frequency profile by proposed method.

records directly. However, to get more geological information which cannot be seen in the foreset sequence, we should use the method which is proposed in this paper to identify the thinner internal sequence and conduct the fine sequence stratigraphic analysis.

\section{Conclusion}

In current seismic sedimentology method, the certain frequency profile with whole stratum information cannot be generated by frequency filtering accurately. A frequency dependent seismic sequence analysis method based on sparse-spiking deconvolution is proposed in this paper. Compared with traditional frequency filtering method, the synthetic example and the actual data show the obvious advantages of proposed method which can accurately obtain the frequency profile with whole stratum information, thus effectively improving the ability of 
seismic interpretation. Low frequency profile tends to characterize thicker litho-stratigraphic units, which is suitable for the stratigraphic framework while high frequency profile can better characterize thinner isochronous-stratigraphic units which is suitable for the fine seismic sequence analysis. Information in a certain frequency profile may not be as rich asoriginal seismic records, but analyzing each frequency profile comprehensively can achieve more detailed geological information, so as to reach the purpose of frequency dependent interpretation. This method is slightly affected by the noise, without too much manual intervention, has strong adaptability and is easy to promote, which is an effective tool for fine sedimentary sequence analysis.

\section{References}

[1] Dong, C. M., Zhang, X. G., and Lin, C. Y. 2006. "Conception Method and Technology of the Seismic Sedimentology.” Acta Sedimentologica Sinica 24 (5): 698-704.

[2] Lin, C. Y., Zhang, X. G., and Dong, C. M. 2007. “Concept of Seismic Sedimentology and Its Prel Iminary Application.” Acta Petrolei Sinica 28 (2): 69-72.

[3] Li, B., Song, Y., He, Y. P., et al. 2009. "Discussion and Application of Seismic Sedimentology.” Acta Geologica Sinica 83 (6): 820-6.

[4] Duan, R. T., Jin, Z. K., Yang, T., et al. 2011. "Methods and Techniques in Seismic Sedimentology Study.” Progress in Geophysics 26 (1): 89-98.

[5] Zeng, H. L., Backus, M., Barrow, K., et al. 1998. "Stratal Slicing, Part I: Realistic 3-D Seismic Model.” Geophysics 63 (2): 502-13.

[6] Zeng, H. L., Henry, S., and Riola, J. 1998. “Stratal Slicing, Part II: Real 3-D Seismic Data.” Geophysics 63 (2): 514-22.

[7] Zeng, H. L. 2004. "Seismic Geomorphology-Based Facies Classification.” The Leading Edge 23 (7): 644-88.

[8] Guo, H. Y., Wu, F. R., Liu, S. G., et al. 2008. “The Preliminary Application of Seismic Sedimentology in Guanggan Area." Computing Techniques for Geophysical and Geochemical Exploration 30 (5): 399-402.

[9] Yin, J. Q., and Yi, Y. J. 2013. "The Application of Seismic Sedimentology in Predicting Deepwater Depositional Reservoirs.” Progress in Geophysics 28 (5): 2626-33.

[10] Zeng, H. L., and Backus, M. 2005. "Interpretive Advantages of $90^{\circ}$-Phase Wavelets: Part 1-Modeling.”
Geophysics 70 (3): C7-15.

[11] Zeng, H. L., and Backus, M. 2005. "Interpretive Advantages of $90^{\circ}$-Phase Wavelets: part 2-Seismic Applications.” Geophysics 70 (3): C17-24.

[12] Zeng, H. L. 2010. "Stratal Slicing: Benefits and Challenges.” The Leading Edge 29 (9): 1040-7.

[13] Zeng, H. L., and Jackson, K. G. 2003. "Seismic Frequency Control on Carbonate Seismic Stratigraphy: A Case Study of the Kingdom Abo Sequence, West Texas.” AAPG Bulletin 87 (2): 273-93.

[14] Zeng, H. L. $2013 . \quad$ "Frequency-Dependent Seismic-Stratigraphic and Facies Interpretation.” $A A P G$ Bulletin 97 (2): 201-21.

[15] Zhu, X. M., Liu, C. L., Zhang, Y. N., et al. 2009. “On Seismic Sedimentology of Lacustrine Deltaic Depositional Systems.” Acta Sedimentologica Sinica 27 (5): 915-21.

[16] Liu, C. L., Zhu, X. M., Hu, Y. S., et al. 2011. “Application of Seismic Sedimentology onLacustrine Turbidite Deposition Indetification.” Journal of Jilin University (Earth Science Edition) 41 (3): 657-64.

[17] Partyka, G., Gridley, J., and Lopez, J. 1999. "Interpretational Applications of Spectral Decomposition in Reservoir Characterization.” The Leading Edge 18 (3): 353-60.

[18] Han, L., Han, L., and Li, Z. 2012. "Inverse Spectral Decomposition with the SPGL1 Algorithm.” Journal of Geophysics and Engineering 9 (4): 423-7.

[19] Han, L., Sacchi, M.D., and Han, L. 2014. "Spectral Decomposition and De-noising via Time-Frequency and Space-Wavenumber Reassignment.” Geophysical Prospecting 62 (2): 244-57.

[20] Zhao, S., Li, Z. D., and Xu, H. M. 2006. "Frequency Division and the Analyse of Its Application for Sandstone FF Continental Facies in Seismic Prospection.” Journal of Mineralogy and Petrology 26 (2): 106-10.

[21] Sacchi, M. D. 1997. "Reweighting Strategies in Seismic Deconvolution.” Geophysical Journal International 129 (3): 651-6.

[22] Liu, X. W., Ning, J. R., Liu, P. T., et al. 2009. “Seismic Time-Frequency Analysis for Frequency Decomposition with Applications to Seismic Sedimentology and Reservoir Imaging.” Progress in Geophysics 24 (5): 1679-88.

[23] Velis, D. R. 2008. "Stochastic Sparse-Spike Deconvolution.” Geophysics 73 (1): R1-9.

[24] Han, L. 2013. "Research on the Methods of High-Resolution Full Spectrum Decomposition.” PhD thesis, Jilin University.

[25] Daubechies, I., Devore, R., Fornasier, M., et al. 2010. "Iteratively Reweighted Least Squares Minimization for Sparse Recovery.” Communications on Pure and Applied Mathematics 63 (1): 1-38. 